\title{
Contraceptive non-use and associated factors among university students in 22 countries.
}

\author{
Karl Peltzer ${ }^{1,2,3}$, Supa Pengpid ${ }^{1,4}$
}

1. ASEAN Institute for Health Development, Madidol University, Salaya, Phutthamonthon, Nakhonpathom, Thailand, 73170

2. Department of Psychology, University of Limpopo, Turfloop, Sovenga 0727, South Africa

3. HIV, STIs and TB (HAST) Research programme, Human Sciences Research Council (HSRC), Pretoria 0001, South Africa

4. Department of Research, University of Limpopo, Turfloop, Sovenga 0727, South Africa.

\begin{abstract}
Background: The aim of this study was to investigate contraceptive non-use and associated factors (socio-demographics, sexual behaviour, internal assets and mental health) among undergraduate university students in 22 countries.

Methods: Using anonymous questionnaires, data was collected from 16979 undergraduate university students (mean age $20.8, \mathrm{SD}=2.8$ ) from 23 universities in 22 countries.

Results: Of the total sample of 16979 undergraduate university students, 7032 (41.9\%) reported to have been sexually active in the past 12 months. Of those who had been sexually active, $42.6 \%$ reported never $(42.7 \%$ among male and $42.6 \%$ among female students) using contraceptives in the past 12 months. In multivariate regression analysis, among both men and women, younger age, religious affiliation (Hindu; and among women only being Muslim), intrinsic religiosity, and sexually protective behaviour were associated with contraceptive non-use. Lack of internal assets (among men, low life satisfaction and lack of personal control, and among women low personal mastery) ; among women not having depressive symptoms and among men having PTSD symptoms were associated with contraceptive non-use.

Conclusion: Low contraceptive use was found and several factors identified as associated with contraceptive non-use may help guide intervention efforts.

Keywords: Birth control, practice, undergraduate students, socio-demographic factors, sexual variables, internal assets, mental health, multi-country.

DOI: http://dx.doi.org/10.4314/ahs.v15i4.2

Cite as: Peltzer K, Pengpid S. Contraceptive non-use and associated factors among university students in 22 countries. Afri Health Sci. 2015;15(4):1056-64. http:// dx.doi.org/10.4314/abs.v15i4.2
\end{abstract}

\section{Introduction}

Adolescents and young adults may experience negative health consequences from early unprotected sexual activity, such as unintended pregnancy, unsafe abortion, sexually transmitted infections (STIs), including HIV, and pregnancy-related mortality and morbidity. ${ }^{1}$ Data from population-based surveys ${ }^{2}$ shows low rates of

\footnotetext{
Corresponding author:

Karl Peltzer,

ASEAN Institute for Health Development, Madidol University, Salaya, Phutthamonthon,

Nakhonpathom, Thailand, 73170

Tel.: +27-12-302-2000,

Fax: +27-12-3022067,

E-mail:kpeltzer@hsrc.ac.za
}

current contraceptive use, among sexually active, never-married women (15-19 years old) in Africa: 31\% in Nigeria (2008), 36\% in Tanzania (2010), 26\% in Zambia (2007), in Asia: 18\% in India (2005) and 4\% in the Philippines (2008), and in Latin America: 59\% in Colombia (2010), and 32\% in Guatemala. Likewise, among sexually active men (15-24 years) in Africa: $42 \%$ in Nigeria (2008), 42\% in Tanzania (2010), and 41\% in Zambia (2007), in Asia: 18\% in India (2005), and in Latin America: $32 \%$ in Guatemala. ${ }^{2}$ Among sexually active university students, the following proportions of lack or contraception non-use were found: in Botswana: Sometimes/never used contraception among male $(20 \%)$ and female $(26 \%)^{3}$; in China $48.7 \%-84 \%$ had not taken contraceptive measures during the episode of first sexual intercourse $e^{4,5}$, in Lebanon: $76 \%$ of females had generally not used contraceptives $(75.6 \%)^{6}$, in Nigeria, only 
$25 \%$ have ever used any contraceptive method $^{7}$ and $66 \%$ were currently not using contraceptives ${ }^{8}$, in South Africa 19\% had not used contraceptives at last sexual encounter ${ }^{9}$, in Uganda 19\% did not use contraception in their last sexual encounter ${ }^{10}$; in Ukraine, $32 \%$ and $19 \%$ did not use contraceptives at their first and most recent sexual intercourse, respectively ${ }^{11}$ and among women in the US, $23 \%$ reported not using contraception. ${ }^{12}$

Globally, "Reasons for a global unmet need for contraception include: limited choice of methods; limited access to contraception, particularly among young people, poorer segments of populations, or unmarried people; fear or experience of side-effects; cultural or religious opposition; poor quality of available services; gender-based barriers." 13 Among university students factors associated with contraceptive non-use for women, men or both can be summarized as follows: 1) socio-demographic factors (younger age, lower educational level ${ }^{10,14,15}$, being male ${ }^{16}$, higher degree of religiosity $^{17,18}$, high price of contraceptives ${ }^{14}$ ); 2) Sexual behaviour (early sexual debut ${ }^{10,16,19}$, not previously pregnant ${ }^{20}$, more than one sexual partner in the past 12 months ${ }^{20}$, internet use (sex ${ }^{21,22}$; Psychosocial factors or internal assets (low locus of control, low personal initiative and assertiveness ${ }^{14}$, lack of life satisfaction ${ }^{23}$, and psychological distress ${ }^{24,25}$ ), and 3) other factors (fear of side effects of modern contraceptives ${ }^{7}$, lack of exposure to healthcare worker talking about contraception ${ }^{12}$ ).

However, only limited research has been conducted on the prevalence and determinants of contraceptive use among youth in developing countries, especially among university students. ${ }^{10}$ This study, therefore, seeks to address this gap by correlating the association between socio-demographic factors, sexual behaviour and risk, internal assets, and mental health variables with nonuse of contraception among university students in 22 countries across Africa, Asia and America.

The aim of this study was to investigate contraceptive non-use and its associated factors (socio-demographics, sexual behaviour, internal assets and mental health) among undergraduate university students in 22 countries.

\section{Methods}

\section{Sample and procedure}

This cross-sectional study was part of a larger investigation on a range of health behaviours in university students, and was carried out with a network of researchers in participating countries (see Acknowledgments). The country selection was a convenient sample, with targeting a large spread of countries in developing countries across Africa, Asia and America. The anonymous, self-administered questionnaire used for data collection was developed in English, then translated and back-translated into languages (Arabic, Bahasa, Chinese, Filipino, French, Lao, Russian, Thai, Turkish) of the participating countries. Research assistants working in the participating universities asked classes of undergraduate students to complete the questionnaire at the end of a teaching class. Classes were recruited according to timetable scheduling using stratified random sampling. Informed consent was obtained from participating students, and the study was conducted in 2013. Participation rates were in most countries over $90 \%$. Ethics approvals were obtained from all participating institutions.

\section{Measures}

Contraceptive use or prevention of unwanted pregnancy was assessed through responses to the question: 'During the past 12 months, how often did you and your partner use any method of birth control?' Six different responses/options were included, never had sexual intercourse, had sexual intercourse but not during the past 12 months, never, rarely, sometimes, most of the time or always used contraceptives. The variable was then dichotomised into $1=$ never used contraceptives and $0=$ rarely, sometimes, most of the time or always.

Pregnancy history: was assessed with the question, "Have you ever made someone pregnant/been pregnant?" Those who responded affirmatively were asked, "How old were you when you first made someone pregnant/became pregnant?"

Sexual variables. The 'number of sexual partners in the past 12 months' was determined by the response to the question: 'How many sexual partners have you had in the past 12 months?' The variable was dichotomised into 1 and 2 or more partners. Alcohol use in the context of sex was assessed for in the past three months, and participants responded to the questions, "Have you ever been diagnosed with a sexually transmitted infection?" "Have you ever been sexually abused as a child?" "How many hours do you spend online for internet sex per week?"

Internal assets. Life satisfaction was assessed with one question, "All things considered, how satisfied are you 
with your life as a whole?" Response options ranged from $1=$ Very satisfied to $5=$ Very dissatisfied. ${ }^{26}$ Three items measured personal mastery (e.g., "I can do just about anything I really set my mind to") and three items perceived constraints (e.g., "I often feel helpless in dealing with the problems of life" ${ }^{27}$. Cronbach's alpha for personal mastery in our sample was 0.75 and for perceived constraints 0.78 .

Intrinsic religiosity (or subjective religiosity) was assessed with three items of The Duke University Religion Index (DUREL). ${ }^{28}$ One item example is, "My religious beliefs are what really lie behind my whole approach to life." Response options ranged from $1=$ definitely not true to $5=$ definitely not true of me. Cronbach alpha for the intrinsic religiosity subscale was 0.81 for this sample.

Socio-demographic questions included age, gender, marital status, and socioeconomic background was assessed by asking survey participants to rate their family background as wealthy (within the highest $25 \%$ in their "country", in terms of wealth), quite well off (within the $50 \%$ to $75 \%$ range for their country), not very well off (within the $25 \%$ to $50 \%$ range from "country"), or quite poor (within the lowest $25 \%$ in their country, in terms of wealth). ${ }^{26}$ Religious affiliation was assessed with the question, "What is your religious denomination?" Response options included: 1. Traditional religion, 2. Christian (Protestant, e.g. Lutheran, Anglican, etc.), 3. Christian (Catholic), 4. Hindu, 5. Moslem, 6. Buddhist, 7. No religion, 8. Other (specify).

Post-traumatic stress disorder (PTSD). A 7-item screen was used to identify PTSD symptoms in the past month. ${ }^{29}$ Items asked whether the respondent had experienced difficulties related to a traumatic experience (e.g., "Did you begin to feel more isolated and distant from other people?"). Consistent with epidemiological evidence, participants who answered affirmatively to at least four of the questions were considered to have a positive screen for PTSD. ${ }^{29}$ The Cronbach alpha reliability coefficient of this 7 -item scale was 0.75 in this study.

Centres for Epidemiologic Studies Depression Scale (CES-D). We assessed depressive symptoms using the 10 -item version of the CES-D. ${ }^{30}$ While the
CES-D 10-item survey has not been directly compared to clinical diagnosis of major depression, the sensitivity and specificity of the CES-D 20-item survey has been reported to average $80 \%$ and $70 \%$, respectively, compared to the formal diagnostic interview. ${ }^{31}$ Scoring is classified from 0-9 as having a mild level of depressive symptoms, 10 to 14 as moderate depressive symptoms, and 15 representing severe depressive symptoms. ${ }^{32}$ The Cronbach alpha reliability coefficient of this 10 -item scale was 0.74 in this study.

\section{Data analysis}

The data was analysed using IBM SPSS (version 20.0). Stratified analysis was conducted for male and female students. The proportion of socio-demographic factors, sexual variables, internal assets, mental health, and contraceptive use was calculated as a percentage.

Logistic regression analysis was done with STATA to calculate the crude odds ratio (OR) with $95 \%$ confidence interval (CI) to determine the associations between the potential determinants and contraception non-use. All variables which were statistically significant $(\mathrm{P}<.05)$ in bivariate analyses were included in the multivariable model. Predictor variables were entered in a single step. The country was entered as the primary sampling unit for survey analysis in STATA in order to achieve accurate CIs, given the clustered nature of the data. ${ }^{26}$

\section{Results}

\section{Sample characteristics}

Of the total sample of 16979 undergraduate university students (mean age 20.8, $\mathrm{SD}=2.8$ ) from 23 universities in 22 countries, $7032(41.9 \%)$ reported to have been sexually active in the past 12 months; $52.1 \%$ among men and $36.2 \%$ among female students. Of those who had been sexually active in the past 12 months, $42.6 \%$ reported never (42.7\% among male and $42.6 \%$ among female students), $33.0 \%$ rarely, sometimes or most of the times and $24.4 \%$ always using contraceptives in the past 12 months. A large variation of contraceptive non-use among sexually active students by country was found, from $91.3 \%$ in India and $89.1 \%$ in Indonesia to between 16-17\% in Colombia and Venezuela. (see Table 1). 
Table 1: Sample characteristics by country

\begin{tabular}{|c|c|c|c|c|c|c|c|c|c|}
\hline & \multirow{2}{*}{$\begin{array}{l}\begin{array}{l}\text { Total } \\
\text { sample }\end{array} \\
\mathrm{N}\end{array}$} & \multirow{2}{*}{$\begin{array}{l}\text { Age } \\
\text { M (SD) }\end{array}$} & \multicolumn{2}{|c|}{$\begin{array}{l}\text { Sexually } \\
(\mathrm{N}=7032)\end{array}$} & \multirow{2}{*}{$\begin{array}{l}\text { active } \\
\text { Femal } \\
\mathrm{e} \\
(\%) \\
\end{array}$} & \multicolumn{2}{|c|}{ Contraceptive non-use } & \multirow[b]{2}{*}{$\begin{array}{l}\text { Male } \\
\%\end{array}$} & \multirow[b]{2}{*}{$\begin{array}{l}\text { Femal } \\
\mathrm{e} \\
\%\end{array}$} \\
\hline & & & $\begin{array}{l}\text { All } \\
(\%)\end{array}$ & $\begin{array}{l}\text { Male } \\
(\%)\end{array}$ & & $\mathrm{N}$ & $\%$ CI $(95 \%)$ & & \\
\hline All & 16979 & $20.8(2.8)$ & 41.9 & 52.1 & 36.2 & 2955 & $42.6(41.5-43.0)$ & 42.7 & 42.6 \\
\hline \multicolumn{10}{|l|}{ Asia } \\
\hline China & 1184 & $19.9(2.2)$ & 13.8 & 20.7 & 12.9 & 69 & $50.5(40.8-60.2)$ & 52.2 & 45.9 \\
\hline India & 800 & $17.9(0.9)$ & 14.5 & 15.0 & 13.5 & 105 & $91.3(86.1-96.5)$ & 92.5 & 88.6 \\
\hline Indonesia & 750 & $18.8(2.9)$ & 24.8 & 27.3 & 23.7 & 67 & $89.1(85.4-94.1)$ & 90.5 & 89.4 \\
\hline Kyrgyzstan & 837 & $21.3(1.5)$ & 44.4 & 77.4 & 19.8 & 133 & $35.8(31.0-40.7)$ & 34.4 & 40.0 \\
\hline Laos & 806 & $22.3(1.9)$ & 34.7 & 48.7 & 27.6 & 171 & $61.1(0.55-66.1)$ & 48.1 & 72.8 \\
\hline Philippines & 968 & $18.3(1.4)$ & 8.9 & 14.4 & 7.0 & 41 & $61.2(49.4-72.9)$ & 60.7 & 61.5 \\
\hline Singapore & 894 & $21.2(1.7)$ & 18.6 & 24.9 & 12.0 & 70 & $42.2(34.6-49.7)$ & 40.2 & 45.3 \\
\hline Thailand & 860 & $20.1(1.3)$ & 34.6 & 55.7 & 26.9 & 95 & $36.5(30.7-42.4)$ & 34.7 & 38.0 \\
\hline Turkey & 800 & $20.6(2.2)$ & 26.5 & 40.0 & 13.0 & 128 & $60.4(53.8-67.0)$ & 58.8 & 65.4 \\
\hline \multicolumn{10}{|l|}{ Africa } \\
\hline Cameroon & 627 & $21.5(2.5)$ & 45.6 & 69.0 & 28.1 & 103 & $36.1(30.6-41.7)$ & 33.2 & 41.6 \\
\hline Ivory Coast & 824 & $23.8(2.7)$ & 73.3 & 77.4 & 69.2 & 187 & $31.0(27.3-34.7)$ & 31.3 & 30.5 \\
\hline Madagascar & 800 & $20.0(1.7)$ & 40.4 & 48.5 & 32.3 & 180 & $55.7(50.3-61.2)$ & 54.1 & 58.1 \\
\hline Mauritius & 501 & $20.9(1.2)$ & 29.5 & 41.1 & 24.3 & 100 & $67.6(60.0-75.1)$ & 69.2 & 66.3 \\
\hline Namibia & 503 & $22.3(4.2)$ & 68.4 & 69.5 & 67.6 & 115 & $33.4(28.4-38.4)$ & 30.5 & 34.9 \\
\hline Nigeria & 820 & $22.3(3.1)$ & 40.0 & 45.4 & 33.6 & 188 & $57.3(52.0-62.7)$ & 54.5 & 61.9 \\
\hline South Africa & 888 & $22.3(3.6)$ & 74.9 & 78.8 & 72.0 & 303 & $47.9(44.0-51.7)$ & 52.8 & 44.0 \\
\hline Tunisia & 960 & $21.1(1.8)$ & 17.1 & 23.1 & 14.2 & 123 & $75.5(68.9-82.1)$ & 54.9 & 91.2 \\
\hline \multicolumn{10}{|c|}{ Caribbean and Latinamerica } \\
\hline Barbados & 580 & $21.1(2.1)$ & 72.6 & 74.7 & 69.6 & 183 & $45.4(40.5-50.3)$ & 49.8 & 39.1 \\
\hline Grenada & 435 & $24.1(6.1)$ & 70.6 & 69.5 & 71.0 & 127 & $41.4(35.8-46.9)$ & 30.6 & 46.6 \\
\hline Jamaica & 762 & $21.0(4.7)$ & 68.8 & 75.8 & 66.5 & 187 & $35.7(31.0-40.7)$ & 43.7 & 32.8 \\
\hline Colombia & 816 & $21.1(3.2)$ & 85.7 & 90.6 & 88.8 & 115 & $16.8(14.0-19.6)$ & 18.9 & 14.9 \\
\hline Venezuela & 564 & $20.5(2.8)$ & 75.5 & 89.6 & 65.7 & 303 & $16.4(12.8-20.1)$ & 18.3 & 14.6 \\
\hline
\end{tabular}

Independent variables description among sexually active participants

Regarding age groups, $21.8 \%$ were in late adolescents, while the majority were in their twenties, $6.9 \%$ were married, and $46.3 \%$ were well-off or wealthy by economic family background. Among the different religious affiliations, Protestant religion was the most prominent (31.4\%), followed by Catholics (29.2\%), Muslims (13.8) and Buddhists (8.1\%). Among men and women having been or made someone pregnant was
17.8\% (among men: $15.5 \%$ and among women $20.1 \%$ ), of which $41.2 \%$ were adolescent pregnancies. Almost a third of the sample $(31.2 \%)$ had two or more sexual partners in the past 12 months, $4.6 \%$ had been sexually abused as a child, $24.1 \%$ drank alcohol in the context of sex in the past 3 months, $7.8 \%$ reported ever being diagnosed with a sexually transmitted infection (STI), and $25.9 \%$ reported internet sex. In terms of mental health, 36.6\% screened positive for moderate or severe depression and $21.1 \%$ for PTSD (see Table 2). 
Table 2: Socio-demographics, sexual behaviour, internal assets, mental health and contraceptive non-use by gender among sexually active participants

\begin{tabular}{|c|c|c|c|}
\hline \multirow[t]{2}{*}{ Variables } & \multirow[t]{2}{*}{ All } & \multicolumn{2}{|c|}{ Contraceptive non-use } \\
\hline & & Men & Women \\
\hline Socio-demographics & $\begin{array}{l}\mathrm{N}(\%) \text { or } \mathrm{M} \\
(\mathrm{SD})\end{array}$ & $\begin{array}{l}\mathrm{N}(\%) \text { or } \mathrm{M} \\
(\mathrm{SD})\end{array}$ & $\begin{array}{l}\mathrm{N}(\%) \text { or } \mathrm{M} \\
(\mathrm{SD})\end{array}$ \\
\hline \multicolumn{4}{|l|}{ Age in years } \\
\hline $17-19$ & $1488(21.8)$ & $353(52.6)$ & $376(47.8)$ \\
\hline $20-21$ & $2343(34.4)$ & $461(40.1)$ & $489(42.3)$ \\
\hline $22-30$ & $2981(43.6)$ & $604(39.8)$ & $554(38.6)$ \\
\hline Married & $483(6.9)$ & $54(35.8)$ & $121(36.4)$ \\
\hline \multicolumn{4}{|l|}{ Economic family background } \\
\hline Wealthy & $281(4.1)$ & $59(37.1)$ & $53(46.1)$ \\
\hline Quite well off & $2924(42.2)$ & $604(41.5)$ & $602(42.3)$ \\
\hline Not well off & $2857(41.2)$ & $571(44.6)$ & $668(43.3)$ \\
\hline Poor & $871(12.6)$ & $205(42.9)$ & $151(39.8)$ \\
\hline \multicolumn{4}{|l|}{ Religious affiliation } \\
\hline Traditional & $295(4.5)$ & $(43.0)$ & $66(45.8)$ \\
\hline Protestant & $2040(31.4)$ & $463(49.5)$ & $458(42.5)$ \\
\hline Catholic & $1895(29.2)$ & $260(29.8)$ & $257(26.0)$ \\
\hline Hindu & $198(3.1)$ & $93(89.9)$ & $66(80.5)$ \\
\hline Muslim & $894(13.8)$ & $285(49.6)$ & $206(65.4)$ \\
\hline Buddhist & $527(8.1)$ & $105(45.9)$ & $151(53.7)$ \\
\hline No/other religion & $641(9.9)$ & $107(31.7)$ & $99(34.3)$ \\
\hline Intrinsic religiosity (range 3-15) & $11.0(3.4)$ & $11.2(3.3)$ & $11.2(3.2)$ \\
\hline \multicolumn{4}{|l|}{ Sexual behaviour and risk } \\
\hline Ever (made someone) pregnant & $1216(17.8)^{*}$ & $143(27.4)$ & $204(29.8)$ \\
\hline Adolescent pregnancy ( $<20$ years) & $505(41.2)$ & $59(28.4)$ & $101(34.7)$ \\
\hline $\begin{array}{l}\text { Two or more sexual partners in the past } 12 \\
\text { months }\end{array}$ & $2049(31.2)$ & $381(27.2)$ & $149(24.0)$ \\
\hline History of STI & $539(7.8)$ & $114(44.7)$ & $119(41.9)$ \\
\hline History of child sexual abuse & $318(4.6)$ & $44(43.1)$ & $73(34.4)$ \\
\hline $\begin{array}{l}\text { Alcohol use in the context of sex in the past } 3 \\
\text { Months }\end{array}$ & $1496(24.1)$ & $225(24.8)$ & $149(25.8)$ \\
\hline Internet sex & $1448(25.9)$ & $387(37.8)$ & $162(41.1)$ \\
\hline \multicolumn{4}{|l|}{ Internal assets } \\
\hline Life satisfaction (range 1-5) & $3.2(1.3)$ & $3.0(1.3)$ & $3.1(1.2)$ \\
\hline Personal mastery (range 3-15) & $11.8(2.9)$ & $11.4(2.9)$ & $11.4(2.9)$ \\
\hline Lack of personal control (range 3-15) & $7.7(3.2)$ & $7.8(3.1)$ & $7.7(3.2)$ \\
\hline \multicolumn{4}{|l|}{ Mental health } \\
\hline Depression (moderate/severe) & $2587(36.6)$ & $525(44.2)$ & $544(40.1)$ \\
\hline PTSD & $1404(21.1)$ & $280(47.5)$ & $334(42.4)$ \\
\hline
\end{tabular}

*20.1\% among women

Associations with contraceptive non-use

Multivariate regression analysis among men found that younger age, religious affiliation (being Hindu but not being a Catholic or having no or other religion), intrinsic religiosity, sexually protective behaviour (not having made someone pregnant, not having had multiple sexual partners, not having had alcohol in the context of sex, and not engaged in internet sex), lack of internal assets (low life satisfaction and lack of personal control) and poor mental health (PTSD symptoms) were associated with contraceptive non-use among sexually active male students. In multivariate regression analysis, among women, it was found that younger age, religious affiliation (being Hindu and Muslim, but notbeing a Catholic), intrinsic religiosity, sexually protective behaviour (not ever being pregnant, not having had multiple 
sexual partners, not having had alcohol in the context of sex), lack of internal assets (low personal mastery) and good mental health (not having depressive symptoms) were associated with contraceptive non-use among sexually active female students (see Table 3).

Table 3: Associations with contraceptive non-use (among sexually active)

\begin{tabular}{|c|c|c|c|c|}
\hline Socio-demographics & $\begin{array}{l}\text { Male } \\
\text { UOR }(95 \% \mathrm{CI})\end{array}$ & AOR $(95 \% \mathrm{CI})$ & $\begin{array}{l}\text { Female } \\
\text { UOR }(95 \% \mathrm{CI})\end{array}$ & AOR $(95 \% \mathrm{CI})$ \\
\hline \multicolumn{5}{|l|}{ Age in years } \\
\hline $17-19$ & 1.00 & 1.00 & 1.00 & 1.00 \\
\hline $20-21$ & $0.60(0.50-0.73)^{* * *}$ & $0.64(0.49-0.84)^{* *}$ & $0.80(0.67-0.96)^{*}$ & $0.73(0.58-0.93)^{* *}$ \\
\hline $22-30$ & $0.60(0.50-0.72)^{* * *}$ & $0.69(0.53-0.89)^{* *}$ & $0.68(0.57-0.82)^{* * *}$ & $0.68(0.54-0.86)^{* * *}$ \\
\hline Married (vs. single) & $0.78(0.52-1.03)$ & --- & $0.75(0.59-0.92)^{*}$ & $0.89(0.64-1.25)$ \\
\hline \multicolumn{5}{|l|}{ Wealth } \\
\hline Wealthy & 1.00 & --- & 1.00 & --- \\
\hline Quite well off & $1.20(0.86-1.69)$ & & $0.86(0.59-1.26)$ & \\
\hline Not well off & $1.36(0.97-1.92)$ & & $0.89(0.61-1.31)$ & \\
\hline Poor & $1.27(0.88-1.87)$ & & $0.78(0.51-1.15)$ & \\
\hline \multicolumn{5}{|l|}{ Religious affiliation } \\
\hline Traditional & 1.00 & 1.00 & 1.00 & 1.00 \\
\hline Protestant & $1.30(0.92-1.84)$ & $1.55(0.93-2.59)$ & $0.87(0.62-1.24)$ & $0.96(0.60-1.53)$ \\
\hline Catholic & $0.56(0.39-0.80)^{* * *}$ & $0.79(0.47-1.31)$ & $0.42(0.29-0.59)^{* * *}$ & $0.57(0.35-0.92)^{*}$ \\
\hline Hindu & $5.59(3.18-9.85)^{* * *}$ & $6.15(2.94-12.88)^{* * *}$ & $4.88(2.58-9.22)^{* * *}$ & $5.70(2.53-12.88)^{* * *}$ \\
\hline Muslim & $1.30(0.91-1.87)$ & $1.58(0.94-2.67)$ & $2.23(1.50-3.34)^{* * *}$ & $2.40(1.42-4.08)^{* * *}$ \\
\hline Buddhist & $1.12(0.74-1.70)$ & $1.43(0.80-2.58)$ & $1.37(0.92-2.05)$ & $1.07(0.61-1.89)$ \\
\hline No/other religion & $0.61(0.41-0.91)^{*}$ & $0.77(0.44-1.35)$ & $0.62(0.41-0.93)$ & $0.79(0.47-1.35)$ \\
\hline \multicolumn{5}{|l|}{ Intrinsic religiosity } \\
\hline Low & 1.00 & 1.00 & 1.00 & 1.00 \\
\hline Medium & $1.49(1.27-1.74)^{* * *}$ & $1.68(1.31-2.14)^{* * *}$ & $1.19(1.02-1.40)^{*}$ & $1.38(1.10-1.76)^{* *}$ \\
\hline High & $1.63(1.37-1.94)^{* * *}$ & $1.76(1.33-2.34)^{* * *}$ & $1.40(1.18-1.66)^{* * *}$ & $1.80(1.35-2.39)^{* * *}$ \\
\hline \multicolumn{5}{|l|}{ Sexual behaviour and risk } \\
\hline $\begin{array}{l}\text { never (made someone) } \\
\text { pregnant }\end{array}$ & $0.45(0.37-0.56)^{* * *}$ & $0.60(0.45-0.80)^{* * *}$ & $0.51(0.42-0.61)^{* * *}$ & $0.70(0.55-0.89)^{* *}$ \\
\hline $\begin{array}{l}\text { Two or more sexual } \\
\text { partners in the past } 12 \\
\text { months (base=1) }\end{array}$ & $0.34(0.30-0.40)^{* * *}$ & $0.48(0.39-0.59)^{* * *}$ & $0.41(0.33-0.50)^{* * *}$ & $0.60(0.47-0.77)^{* * *}$ \\
\hline History of STI & $1.12(0.86-1.44)$ & --- & $0.98(0.70-1.26)$ & --- \\
\hline $\begin{array}{l}\text { History of child sexual } \\
\text { Abuse }\end{array}$ & $1.03(0.69-1.53)$ & --- & $0.70(0.52-0.93)^{*}$ & $0.88(0.60-1.29)$ \\
\hline $\begin{array}{l}\text { Alcohol use in the context } \\
\text { of sex in the past } 3 \text { months }\end{array}$ & $0.41(0.34-0.49)^{* * *}$ & $0.66(0.52-0.83)^{* * *}$ & $0.51(0.41-0.62)^{* * *}$ & $0.75(0.59-0.96)^{*}$ \\
\hline Internet sex & $0.83(0.71-0.97)^{*}$ & $0.88(0.71-1.10)$ & $1.08(0.87-1.35)$ & --- \\
\hline \multicolumn{5}{|l|}{ Internal assets } \\
\hline Life satisfaction & $0.82(0.78-0.86)^{* * *}$ & $0.88(0.82-0.95)^{* * *}$ & $0.94(0.82-0.99)^{*}$ & $0.95(0.88-1.03)$ \\
\hline \multicolumn{5}{|l|}{ Personal mastery } \\
\hline Low & 1.00 & 1.00 & 1.00 & 1.00 \\
\hline Medium & $0.78(0.66-0.93)^{* *}$ & $0.91(0.71-1.16)$ & $0.67(0.56-0.79)^{* * *}$ & $0.70(0.53-0.81)^{* *}$ \\
\hline High & $0.65(0.55-0.78)^{* * *}$ & $0.78(0.60-1.02)$ & $0.58(0.48-0.69)^{* * *}$ & $0.66(0.49-0.88)^{* *}$ \\
\hline \multicolumn{5}{|l|}{ Lack of personal control } \\
\hline Low & 1.00 & 1.00 & 1.00 & 1.00 \\
\hline Medium & $1.35(1.16-1.59)^{* * *}$ & $1.50(1.20-1.88)^{* * *}$ & $1.24(1.06-1.46)^{* *}$ & $1.16(0.93-1.45)$ \\
\hline High & $1.52(1.28-1.81)^{* * *}$ & $1.31(1.01-1.69)^{*}$ & $1.25(1.06-1.48)^{* *}$ & $1.20(0.96-1.51))$ \\
\hline \multicolumn{5}{|l|}{ Mental health } \\
\hline $\begin{array}{l}\text { Depression } \\
\text { (moderate/severe) }\end{array}$ & $1.19(0.98-1.27)$ & --- & $0.84(0.73-0.97)^{*}$ & $0.82(0.68-0.99)^{*}$ \\
\hline PTSD & $1.27(1.06-1.52)^{* *}$ & $1.45(1.12-1.87)^{* *}$ & $1.03(0.87-1.21)$ & -- \\
\hline
\end{tabular}

*** $\mathrm{p}<0.001, * * \mathrm{p}<0.01, * \mathrm{p}<0.05$, UOR, Unadjusted Odds Ratio; AOR, Adjusted Odds Ratio; CI, Confidence Interval. 


\section{Discussion}

The results of this large study among university students in 22 countries found that by the age of 21 years, over $20 \%$ of sexually active women reported to have been pregnant, yet only $57.4 \%$ of sexually active students reported using contraception. This study is a significant contribution to the literature as it presents data from a very large sample of an understudied and important population, university students. The overall rate of $42.6 \%$ contraceptive non-use among sexually active students in this sample seem comparable to studies among university students in China ${ }^{4,5}$ and Nigeria. ${ }^{6,7}$ A large variation of contraceptive non-use among sexually active students by country was found, from $91.3 \%$ in India and $89.1 \%$ in Indonesia to between 16-17\% in Colombia and Venezuela. These country variations seem similar to those in population survey-based observations among never married 15-19 year old women and 15-24 year old men, where modern contraceptive non-use in Nigeria was among women $69 \%$ and men $58 \%$, in India (women $82 \%$ and men $82 \%$ ), in the Philippines 96\% among women, and in Colombia 41\% among women. ${ }^{2}$

The study found, in agreement with other studies $^{10,14,15,17,18}$, that younger age, a higher degree of religiosity or intrinsic religiosity and religious affiliation (Hindu and Muslim) were associated with contraception non-use. According to $\mathrm{WHO}^{13}$, reasons for a global unmet need for contraception particularly include young people and cultural or religious opposition. ${ }^{13}$ Regarding sexual behaviour and risk, this study found that among men and women not having made someone or ever being pregnant previously was associated with non-contraception use, which was also found in a study among South African youth. ${ }^{20}$ It is possible that only after the first pregnancy are young men and women are educated about and subsequently offered contraceptive services. ${ }^{20}$ Unlike in a previous study among South African youth, which found that having more than one sexual partner in the past 12 months was associated with contraception non-use ${ }^{20}$, this study found that sexually protective behaviour (not having had multiple sexual partners and not having had alcohol in the context of sex) were associated with contraceptive non-use among sexually active students. It is possible that there is a lesser felt need for the use of contraception in a one partner sexual relationship than it is with multiple sexual partners. Interesting is the finding that alcohol use in the context of sex did not have a negative effect on contraceptive use, as other studies seem to find that alcohol use may lead to greater risk-taking behaviour including contraception non-use in casual relationships. ${ }^{33}$

In agreement with other studies ${ }^{14,23}$, this study also found that lack of internal assets (among men low life satisfaction and lack of personal control, and among women low personal mastery) was associated with contraceptive non-use. This study found that among men poor mental health (PTSD symptoms) while not having depressive symptoms among women were associated with contraceptive non-use. Previous studies found that elevated levels of anxiety or depression had been associated with sexual risk-taking behaviour such as inconsistent condom use. ${ }^{34,35}$ Other studies ${ }^{24,25}$ found that women's psychological symptoms predicted their contraceptive non-use and use of less effective methods. We did not however assess the type of contraceptive method used. It is possible that women with poor mental health in this study would have more frequently selected less effective contraceptive methods such as condom or withdrawal and those with good mental health more effective, permanent contraceptive methods.

\section{Study limitations}

This study was only conducted in one university in each country, the results are therefore not necessarily generalisable to other parts of each country. Furthermore, only participants who were studying at a university were included, which means that those who were not in a university were excluded. Also, certain risk factors for contraceptive non-use such as the type of contraceptives used, reasons of non-use ${ }^{9}$, contraceptive knowledge $\mathrm{e}^{4}$ and healthcare worker communication about using contraception were not included, and should be included in future studies. ${ }^{12}$

\section{Conclusion}

Among this university student population high contraceptive non-use was observed. Socio-demographic factors, sexually protective behaviour, lack of internal assets and mental health status were identified as risk factors for contraceptive non-use. Sexual and reproductive health policies and programmes should be designed to take these identified risk factors into account. 


\section{Acknowledgements}

Partial funding for this study was provided by the South African Department of Higher Education. The following colleagues participated in this student health survey and contributed to data collection (locations of universities in parentheses) Barbados: T. Alafia Samuels (Bridgetown); Cameroon: Jacques Philippe Tsala Tsala (Yaounde); China: Tony Yung and Xiaoyan Xu (Hong Kong and Chengdu); Colombia: Carolina Mantilla (Pamplona); Grenada: Omowale Amuleru-Marshall (St. George); India: Krishna Mohan (Visakhapatnam); Indonesia: Indri Hapsari Susilowati (Jakarta); Ivory Coast: Issaka Tiembre (Abidjan); Jamaica: Caryl James (Kingston); Kyrgyzstan: Erkin M Mirrakhimov (Bishkek); Laos: Vanphanom Sychareun (Vientiane); Madagascar: Onya H Rahamefy (Antananarivo); Mauritius: Hemant Kumar Kassean (Réduit, Moka); Namibia: Pempelani Mufune (Windhook); Nigeria: Solu Olowu (Ile-Ife); Philippines: Alice Ferrer (Miagao); Singapore: Mee Lian Wong (Singapore); South Africa: Tholene Sodi (Polokwane); Thailand: Tawatchai Apidechkul (Chiang Rai); Tunisia: Hajer Aounallah-Skhiri (Tunis); Turkey: Neslihan Keser Özcan (Istanbul); Venezuela: Yajaira M Bastardo (Caracas).

\section{References}

1. Chandra-Mouli V, McCarraher DR, Phillips SJ, Williamson NE, Hainsworth G. Contraception for adolescents in low and middle income countries: needs, barriers, and access. Reprod Health 2014;11(1):1. doi: 10.1186/1742-4755-11-1.

2. Anderson R, Panchaud C, Singh S, Watson K. Demystifying data: A guide to using evidence to improve young people's sexual health and rights, New York: Guttmacher Institute, 2013.

3. Hoque ME, Ntsipe T, Mokgatle-Nthabu M. Awareness and practices of contraceptive use among university students in Botswana. 2013;10(2):83-8.

4. Zhou YZ, Zhang MM, Wei S, Guan HT, Yin P, Ren N, Pang XB, Xiong CL. Survey on knowledge, attitude, practice related to contraception among college students in Beijing. Zhonghua Liu Xing Bing Xue Za Zhi 2009;30(7):710-2.

5. Li A, Li L, Ma C. A survey on contraceptive awareness, attitudes and practice among university students in Beijing. Chinese J Fam Plann 2000;8(3):112-115, 143-144. 6. Barbour B, Salameh P. Knowledge and practice of university students in Lebanon regarding contraception. East Mediterr Health J 2009;15(2):387-99.

7. Abiodun OM, Balogun OR. Sexual activity and contraceptive use among young female students of tertiary educational institutions in Ilorin, Nigeria. Contraception 2009;79(2):146-9.

8. Arowojolu AO, Ilesanmi AO, Roberts OA, Okunola MA. Sexuality, contraceptive choice and AIDS awareness among Nigerian undergraduates. Afr $J$ Reprod Health 2002;6(2):60-70.

9. Hoque M, Ghuman S. Contraceptive practices in the era of HIV/AIDS among university students in KwaZulu-Natal, South Africa. SAHARA J 2012;9(1):15-9.

10. Mehra D, Agardh A, Petterson KO, Östergren PO. Non-use of contraception: determinants among Ugandan university students. Glob Health Action 2012;5:18599. PubMed doi: 10.3402/gha.v5i0.18599.

11. Mogilevkina I, Tydén T, Odlind V. Ukrainian medical students' experiences, attitudes, and knowledge about reproductive health. J Am Coll Health 2001;49(6):269 PubMed -72 .

12. Huber LR, Ersek JL. Contraceptive use among sexually active university students. J Womens Health 2009;18(7):1063-70.

13. World Health Organization (WHO). Fact sheet: Family planning. Retrieved at http://www.who.int/mediacentre/factsheets/fs351/en/, 2013.

14. Bjelica A, Trninić-Pjević A. Review of identified factors influencing contraceptive use. Med Pregl 2008;61(34):151-5.

15. Siegel DM, Klein DI, Roghmann KJ. Sexual behavior, contraception, and risk among college students. $J$ Adolesc Health 1999;25(5):336-43.

16. Tafuri S, Martinelli D, Germinario C, Prato R. A study on the sexual and contraception behaviours of the pre-university students in Puglia (South-Italy). J Prev Med Hyg 2011; 52(4):219-23.

17. Notzer N, , Mashiach S, Soffer S. Effect of religiosity on sex attitudes, experience and contraception among university students. J Sex Marital Ther 1984; 10(1):57-62. 18. Moreau C, Trussell J, Bajos N. Religiosity, religious affiliation, and patterns of sexual activity and contraceptive use in France. Eur J Contracept Reprod Health Care 2013; 18(3):168-80.

19. Seutlwadi L, Peltzer K, Mchunu G, Tutshana BO. Contraceptive use and associated factors among South African youth (18 - 24 years): A population-based survey. S Afr J Obstet Gynaec 2012;8(2): 43-47.

20. MacPhail C, Pettifor AE, Pascoe S, Rees HV. Contraceptive use and pregnancy among 15-24 year old South African women: a nationally representative cross-sectional survey. BMC Med 2007;5:31.

21. Adebayo DO, Udegbe IB, Sunmola AM. Gender, Internet use, and sexual behavior orientation among young Nigerians. Cyberpsychol Behav 2006;9(6):742-52. 
22. Hald GM, Mulya TW. Pornography consumption and non-marital sexual behaviour in a sample of young Indonesian university students. Cult Health Sex 2013;15(8):981-96.

23. Morrison L. Contraceptive use among emerging adult college women: Results from a national survey. PhD Thesis, Faculty of University of Minnesota School of Nursing, 2013.

24. Farr SL, Curtis KM, Robbins CL, Zapata LB, Dietz PM. Use of contraception among US women with frequent mental distress. Contraception 2011;83:127-133 PubMed .

25. Garbers S, Correa N, Tobier N, Blust S, Chiasson MA. Associations between symptoms of depression and contraceptive method choices among low-come women at urban reproductive health centers. Matern Child Health 2010;14:102-109 PubMed .

26. Steptoe A, Wardle J. Cognitive predictors of health behaviour in contrasting regions of Europe. Br J Clin Psychol 1992;31: 485-502.

27. Lachman ME, Weaver SL. The sense of control as a moderator of social class differences in health and well-being. J Person Soc Psychol 1998;74(3):763-773.

28. Koenig HG, Büssing A. The Duke University Religion Index (DUREL): A five-item measure for use in epidemological studies. Religions 2010;1:78-85.

29. Kimerling R, Ouimette P, Prins A, Nisco P, Lawler C, Cronkite R, Moos RH. Brief report: Utility of a short screening scale for DSM-IV PTSD in primary care. J Gen Intern Med 2006;21(1): 65-67.

30. Andresen EM, Malmgren JA, Carter WB, Patrick DL. Screening for depression in well older adults: Evaluation of a short form of the CES-D (Center for Epidemiologic Studies Depression Scale). Am J Prev Med 1994;10(2): 77-84.

31. Mulrow CD, Williams JWJr, Gerety MB, Ramirez G, Montiel OM, Kerber, C. Case-finding instruments for depression in primary care settings. Ann Intern Med 1995;122:913-921.

32. Kilbourne AM, Justice AC, Rollman BL, McGinnis KA, Rabeneck L, Weissman S, Smola S, Schultz R, Whittle J, Rodriguez-Barradas M. Clinical importance of HIV and depressive symptoms among veterans with HIV infection. J Gen Intern Med 2002;17(7):512-20.

33. Brown JL, Vanable PA. Alcohol use, partner type, and risky sexual behavior among college students: findings from an event level study. Addict Behav 2007; 32: 2940-52 PubMed .

34. Agardh A, Cantor-Graae E, Ostergren PO. Youth, sexual risk-taking behavior, and mental health: a study of university students in Uganda. Int J Behav Med. 2012;19(2):208-16.

35. Pengpid S, Peltzer K, Skaal L. Mental health and HIV sexual risk behaviour among University of Limpopo students in South Africa. S Afr J Psychiat 2013;19(2): 25 PubMed -30 . 